\title{
TRANSPLANTE DE MEDULA ÓSSEA NO NORDESTE BRASILEIRO: RESULTADOS DOS 100 PRIMEIROS TRANSPLANTES NA BAHIA ${ }^{1}$
}

\author{
Bone Marrow Transplantation in the Brazilian Northeast: \\ Results of the first 100 transplants in Bahia State \\ Ronald Pallotta', Flávia Cal², Luciana Landeiro ${ }^{5}$, Ledivia Espinheira ${ }^{3}$, Thereza Christina Cruz Dias ${ }^{4}$, \\ Thyago Espírito Santo ${ }^{5}$, Tiago Pinto ${ }^{5}$
}

\section{RESUMO}

Objetivo: Este relato apresenta a evolução dos 100 primeiros pacientes transplantados na Unidade de Transplante de Medula Óssea do Hospital Português, no período de fevereiro de 2000 a novembro de 2005. Por ser pioneira na Bahia, e uma das únicas referências para este procedimento nas regiões norte e nordeste, fica determinada a importância e peculiaridade do trabalho desta unidade. Métodos: Foram avaliados 48 transplantes alogênicos convencionais, cinco alogênicos não mieloablativos (mini-alo) e 47 autólogos. A idade mediana foi de 31 anos, havendo um predomínio do sexo masculino (59\%) sobre o feminino (41\%). As indicações foram: leucemia mielóide crônica (20), anemia aplástica grave (11), leucemia mielóide aguda (07), síndrome mielodisplásica (06), leucemia linfoblástica aguda (04), linfoma não Hodgkin (12), doença de Hodgkin (13), mieloma múltiplo (21) e doença auto-imune (06). Resultados: A sobrevida global em cinco anos foi de 52\%, sendo $60 \%$ para TMO autólogo, $47 \%$ para TMO alogênico convencional e $40 \%$ para mini-alo. Observamos uma mortalidade nos 100 primeiros dias de $31 \%$, sendo 17\% para TMO autólogo, 46\% para TMO alogênico convencional e 20\% para mini-alo. Conclusão: Os dados demonstram que, apesar de todas as dificuldades impostas pela situação sócio-econômica e cultural desta região, o TMO é um procedimento factível e apresenta resultados satisfatórios, que não divergem de outros grandes centros transplantadores do país e do mundo.

Descritores: Transplante de Medula Óssea, Imunologia, Rejeção do Enxêrto.
Grau Acadêmico:
1. Professor de Onco-hematologia
2. Médica Clínica Pediátrica
3. Médica Clínica Infectologista
4. Médica Clínica Anestesiologista
5. Acadêmico(a) de Medicina

Instituições:

Hospital Português da Bahia e Núcleo de Onco-Hematologia do Departamento de Clínica Médica da Escola Bahiana de Medicina e Saúde Pública

\section{Correspondência:}

Dr. Ronald Pallotta - Av. Oceânica oㅜ 3529, 403a - Ondina

CEP 40295050 - Salvador - BA - Brasil

Tel: $55713334-5101$

E-mail: tmobahia@yahoo.com.br

Recebido em: 13/12/2005

\section{INTRODUÇÃO}

O transplante de células progenitoras hematopoéticas, também conhecido como transplante de medula óssea (TMO), éum procedimento terapêutico convencional e fundamental para o tratamento de doenças hematológicas, oncológicas e imunológicas. $1,2,3,4,5,6,7,7,9,10,11$

Caracteriza-se pela eliminação dos sistemas hematopoético e imunológico de um indivíduo por quimioterapia, associado ou não à radiação, com subseqüente substituição por células-tronco de outro indivíduo (TMO alogênico) ou previamente coletadas do próprio paciente (TMO autólogo).12,13

A indicação do TMO como opção terapêutica é complexa e depende de fatores como gravidade, subtipo e status da doença, bem como idade e, no caso do transplante alogênico, disponibilidade de doador. ${ }^{2,3,4,6,13,14}$

No Brasil, um país de dimensões continentais, há uma concentração de centros que realizam este procedimento nas regiões sul e sudeste.

A unidade de transplante de medula óssea (UTMO) do Hospital Português da Bahia foi fundada em 2000, com a finalidade de ser a referência para pacientes que necessitem destes procedimentos no estado, bem como ser a contra-referência de pacientes baianos transplantados em outros centros. 
Este relato tem como objetivo descrever os resultados dos primeiros 100 pacientes transplantados na UTMO do Hospital Português da Bahia que, por ser pioneira no estado e um dos únicos centros transplantadores das regiões norte e nordeste, tem determinada a peculiaridade e a importância do seu trabalho.

\section{MÉTODOS}

Nos 100 transplantes realizados, as células-tronco hematopoéticas (CTH) foram infundidas por via endovenosa após o regime de condicionamento, o que se considera dia zero (D0). Estas foram obtidas da medula óssea através de múltiplas aspirações da crista ilíaca posterior, sob bloqueio, em centro cirúrgico, conforme a técnica universal. ${ }^{1} \mathrm{O}$ objetivo foi de coletar 3 a $5 \mathrm{ml}$ de aspirado medular por punção, até um volume total equivalente a $10-15 \mathrm{ml} /$ $\mathrm{kg}$ do receptor. O material aspirado ficou em solução heparinizada, até que o volume final fosse obtido. Posteriormente, ocorreu filtração da solução final e transferência para bolsas coletoras que foram encaminhadas para congelamento (TMO autólogo) ou diretamente para o receptor (TMO alogênico). O menor número de células mononucleares coletadas aceitáveis para realização do procedimento foi de $1,0 \times 10^{8}$ células nucleadas totais por quilograma de peso do receptor.

Outra fonte de CTH foi o sangue periférico a partir da separação de células por leucoaférese utilizando a Fenwall Baxter CS 3000 plus. Para tal opção foi necessária mobilização com corticóide e fator de crescimento granulocítico (GCSF) na dose de 5 a $10 \mathrm{mcg} /$ $\mathrm{kg}$, associada ou não ao purging in vivo com ciclofosfamida. $\mathrm{O}$ menor número de células CD 34+ aceitáveis para realização do procedimento foi de 3,0 × 10 $/ \mathrm{Kg}$. Do mesmo modo, após a coleta, estas foram encaminhadas para congelamento (TMO autólogo) ou para o receptor (TMO alogênico).

O regime de condicionamento utilizado variou de acordo com a modalidade e indicação do TMO. Os principais regimes utilizados para os transplantes alogênicos foram o BuCy4 para AAG, que se caracteriza por bussulfano $4 \mathrm{mg} / \mathrm{kg}$ associado a ciclofosfamida $200 \mathrm{mg} / \mathrm{kg}$; o BuCy2 utilizado para LMC,SMD e LMA, que se caracteriza por bussulfano $16 \mathrm{mg} / \mathrm{kg}$ associado a ciclofosfamida 120 $\mathrm{mg} / \mathrm{kg}$ e o BuMel utilizado para os linfomas, que se caracteriza por bussulfano $16 \mathrm{mg} / \mathrm{kg}$ associado a melfalano $140 \mathrm{mg} / \mathrm{m}^{2}$.

Para os transplantes autólogos foram utilizados, como regimes, irradiação corporal total $800 \mathrm{cGy}$ associado a melfalano $140 \mathrm{mg} /$ $\mathrm{m}^{2}$, o BEAM (carmustina, etoposide, arabinosídeo-c e melfalano) e o CVB (ciclofosfamida, etoposide e carmustina) para os linfomas; o melfalano $200 \mathrm{mg} / \mathrm{m}^{2}$ para o MM e para as DAÍ foi utilizado esquema combinando fludarabina, ciclofosfamida e timoglobulina.

Nos transplantes não-mieloablativos foram utilizados regimes associando a fludarabina ao melfalano.

Todos os pacientes admitidos para TMO receberam profilaxias parasitárias com albendazol (400mg/dia, por três dias) e tinidazol (2g/dia, dose única), e para Pneumociste carinii com sulfametoxazol-trimetropim (1,6g/dia, por sete dias) no período que antecedeu o condicionamento. As culturas de vigilância (swab nasal, oromucosa, pele, anal, peniano ou vaginal, hemoculturas e uroculturas) foram colhidas no momento da admissão.

A profilaxia para fungos foi realizada com fluconazol (400mg/dia), e para vírus, com aciclovir $(800 \mathrm{mg} / \mathrm{dia})$. Estas foram instituídas no momento em que o paciente desenvolveu neutropenia grave (neutrófilos $<500$ ), e mantidas até sete e 30 dias após a enxertia, respectivamente.

O fator estimulante de granulócito (GCSF) foi introduzido no momento em que os pacientes apresentaram contagem leucocitária inferior a 500, na dose de $10 \mathrm{mcg} / \mathrm{kg} / \mathrm{dia}$, e mantido até leucometria maior que $2000 / \mathrm{mm}^{3}$.

Os critérios para transfusão de hemocomponentes foram clínicos ou dependentes de valores hematimétricos para manter $\mathrm{Hb}>8,0$ $\mathrm{g} / \mathrm{dl}$ e plaquetas $>20000 / \mathrm{mm}^{3}$. Todos foram administrados com irradiação prévia e com filtro leucocitário.

A profilaxia para doença do enxerto contra o hospedeiro (DECH), realizada no transplante alogênico foi de acordo com os protocolos vigentes na unidade e o tipo de condicionamento (mieloablativo convencionais ou não-mieloablativo). Vinte e cinco pacientes receberam metotrexato (MTX) na dose de $15 \mathrm{mg} / \mathrm{m}^{2}$ no D1 e $10 \mathrm{mg} / \mathrm{m} 2$ D3,D6,D11 pós-transplante, associado a ciclosporina (CSA) na dose de $3 \mathrm{mg} / \mathrm{kg}$ por via endovenosa, 17 pacientes CSA $(3 \mathrm{mg} / \mathrm{kg}$ ) associado a micofenolato mofetil (MMF) na dose de $1 \mathrm{~g} / \mathrm{d}$ por via oral e 11 pacientes CSA $(3 \mathrm{mg} / \mathrm{kg})$ associado a MMF (1g/d) e $\operatorname{MTX}\left(15 \mathrm{mg} / \mathrm{m}^{2}\right.$ no D1 e $10 \mathrm{mg} / \mathrm{m}^{2}$ no D3 e D6.

$\mathrm{O}$ tempo de seguimento foi calculado como o intervalo entre a data do transplante até a data do óbito, ou até 12/02/2006 para os que estavam vivos. As estimativas das probabilidades de sobrevida acumulada foram feitas pelo estimador produto-limite de Kaplan Meyer e as comparações entre as curvas, pelo teste do log rank.

\section{RESULTADOS}

No período de 01 de fevereiro de 2000 a 30 de novembro de 2005 , foram realizados 100 procedimentos, sendo 48 alogênicos convencionais, cinco alogênicos não-mieloablativos (mini-alo) e 47 autólogos. A mediana de idade foi de 31 anos, variando de oito a 67 , havendo um predomínio do sexo masculino (59\%) sobre o feminino $(41 \%)$.

As indicações foram: leucemia mielóide crônica (20), anemia aplástica grave (11), leucemia mielóide aguda (07), síndrome mielodisplásica (06), leucemia linfoblástica aguda (04), linfoma não-Hodgkin (12), doença de Hodgkin (13), mieloma múltiplo (21) e doença auto-imune (06). As principais características da população estudada encontram-se na tabela 1.

Pode se observar que o seguimento mediano foi de 1216 dias (variando de 997 a 2200) e a sobrevida global (SG) em cinco anos foi de $52 \%$ (fig. 1).

Quando analisamos a SG aos cinco anos, de acordo com o tipo de TMO, observamos que no TMO autólogo a SG foi de $60 \%$, no TMO alogênico foi de $47 \%$ e no mini-alo foi de $40 \%$ (fig. 2).

A SG, de acordo com o diagnóstico, demonstra que, para a LMC, esta foi de $57 \%$, para DH de $37 \%$ e para o LNH de $29 \%$. A SG em dois anos para o MM foi de $80 \%$, para LMA de $57 \%$ e LLA de $50 \%$ (Tabela 2).

A mortalidade nos 100 primeiros dias foi de $31 \%$, sendo $17 \%$ no TMO autólogo, $46 \%$ no alogênico e $20 \%$ no mini-alo. Quando avaliamos as causas de óbito, observamos no TMO alogênico: 
Tabela 1: Características dos 100 pacientes submetidos a transplante de medula óssea no Hospital Português da Bahia.

\begin{tabular}{lccccccccc}
\hline & LMC & DH & LMA & MM & LNH & LLA & AAG & SMD & DAI \\
\hline $\mathbf{N}$ & 20 & 13 & 07 & 21 & 12 & 04 & 11 & 06 & 06 \\
Idade & 31 anos (variando de $8 \mathrm{a} 67$ anos) & & & & \\
Gênero fem/masc. & $41 / 59$ & & & & & & & & \\
Alo (mini-alo) & $19(1)$ & $1(0)$ & $6(0)$ & $0(1)$ & $1(3)$ & $4(0)$ & $11(0)$ & $6(0)$ & $0(0)$ \\
Auto & 0 & 12 & 1 & 20 & 8 & 0 & 0 & 0 & 6 \\
RC/refratários & $0 / 21$ & $1 / 12$ & $3 / 5$ & $8 / 12$ & $4 / 9$ & $3 / 1$ & $0 / 12$ & $0 / 6$ & $0 / 6$ \\
\hline
\end{tabular}

Fem: feminino; mas: masculino; alo:alogênico; mini-alo: minialogênico; auto: autólogo; RC: remissão completa; LMC: leucemia mielóide crônica; DH: doença de Hodgkin; LMA: leucemia mielóide aguda; MM: mieloma múltiplo; LNH: linfoma não-Hodgkin; LLA: leucemia linfóide aguda; AAG: anemia aplásica; SMD: síndrome mielodisplásica; DAl: doenças auto-imunes.

Tabela 2: Sobrevida Global dos 100 pacientes submetidos a transplante de medula óssea no Hospital Português-BA.

\begin{tabular}{ccccccc}
\hline Mediana & $\begin{array}{c}\mathbf{1 0 0} \\
\text { dias }\end{array}$ & $\begin{array}{c}\mathbf{1} \\
\text { ano }\end{array}$ & $\begin{array}{c}\mathbf{2} \\
\text { anos }\end{array}$ & $\begin{array}{c}\mathbf{5} \\
\text { anos }\end{array}$ & $\begin{array}{c}\text { Valor } \\
\mathbf{P}\end{array}$ \\
\hline Série total & $1216(997-2200)$ & $69 \%$ & $58 \%$ & $52 \%$ & $52 \%$ & - \\
\hline Tipo & & & & & & \\
Autólogo & $1240(954-1960)$ & $83 \%$ & $70 \%$ & $60 \%$ & $60 \%$ & 0,09 \\
Alogênico & $1055(748-2200)$ & $54 \%$ & $47 \%$ & $47 \%$ & $47 \%$ & \\
Mini-alo & $680(203-1300)$ & $80 \%$ & $60 \%$ & $40 \%$ & $40 \%$ & \\
Diagnóstico & & & & & & \\
DAI & $54(122-335)$ & $66 \%$ & NA & NA & NA & 0,02 \\
SMD & $34(17-50)$ & $0 \%$ & - & - & - & \\
AAG & $709(341-1078)$ & $54 \%$ & $54 \%$ & $54 \%$ & NA & \\
MM & $947(784-1109)$ & $100 \%$ & $89 \%$ & $80 \%$ & NA & 0,14 \\
DH & $817(342-1960)$ & $61 \%$ & $46 \%$ & $37 \%$ & $37 \%$ & \\
LNH & $586(201-1300)$ & $75 \%$ & $58 \%$ & $29 \%$ & $29 \%$ & \\
LMC & $1288(808-2200)$ & $75 \%$ & $57 \%$ & $57 \%$ & $57 \%$ & \\
LMA & $840(329-1351)$ & $57 \%$ & $57 \%$ & $57 \%$ & NA & \\
LLA & $553(82-1025)$ & $50 \%$ & $50 \%$ & $50 \%$ & NA & \\
\hline
\end{tabular}

Abreviações: LMC: leucemia mielóide crônica; DH: doença de Hodgkin; LMA: leucemia mielóide aguda; MM: mieloma múltiplo; LNH: linfoma não-Hodgkin; LLA: leucemia linfóide aguda; AAG: anemia aplásica; SMD: síndrome mielodisplásica; DAl: doenças auto-imunes.

DECH $(38,2 \%)$, sepse $(19,1 \%)$, recidiva $(9,5 \%)$, HAD $(9,5 \%)$, rejeição (14,3\%), cistite hemorrágica (4,7\%) e IAM (4,7\%). No TMO autólogo a sepse $(71,4 \%)$ e a hemorragia alveolar difusa $(28,6 \%)$ e no mini-alo o único caso foi de sepse.

Dentre as complicações, a mais relevante foi a DECH. No TMO alogênico a taxa de ocorrência de DECH grau $\geq 2$ foi de $35,6 \%$.
Figura 1. Sobrevida Global dos pacientes submetidos a transplante de medula óssea na Bahia

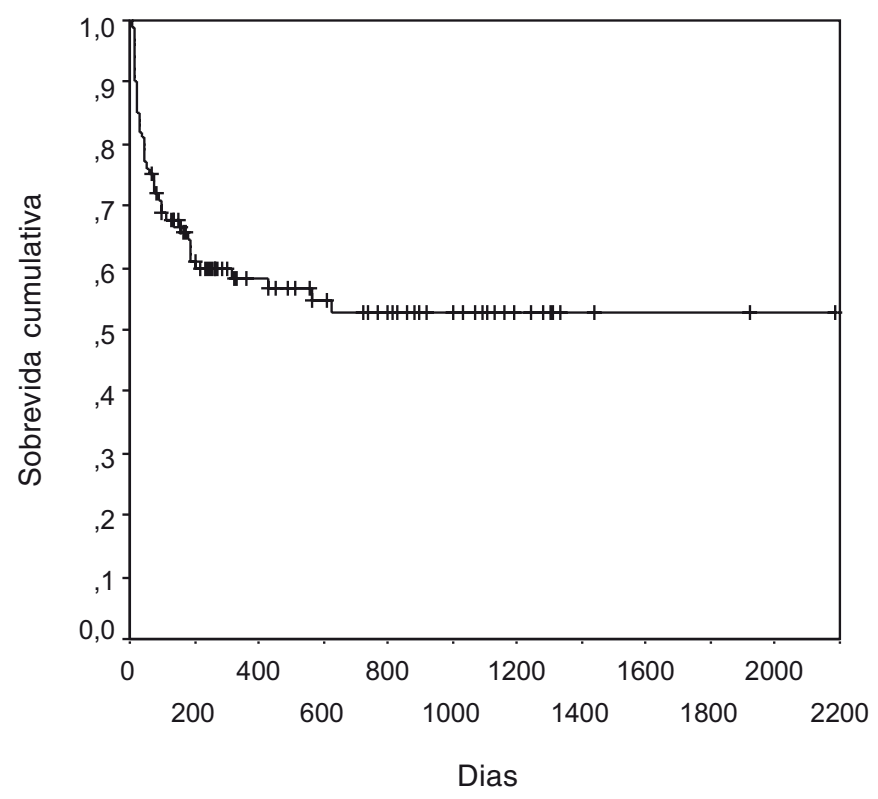

Figura 2. Sobrevida dos pacientes submetidos a transplante de medula óssea na Bahia de acordo com o tipo de transplante

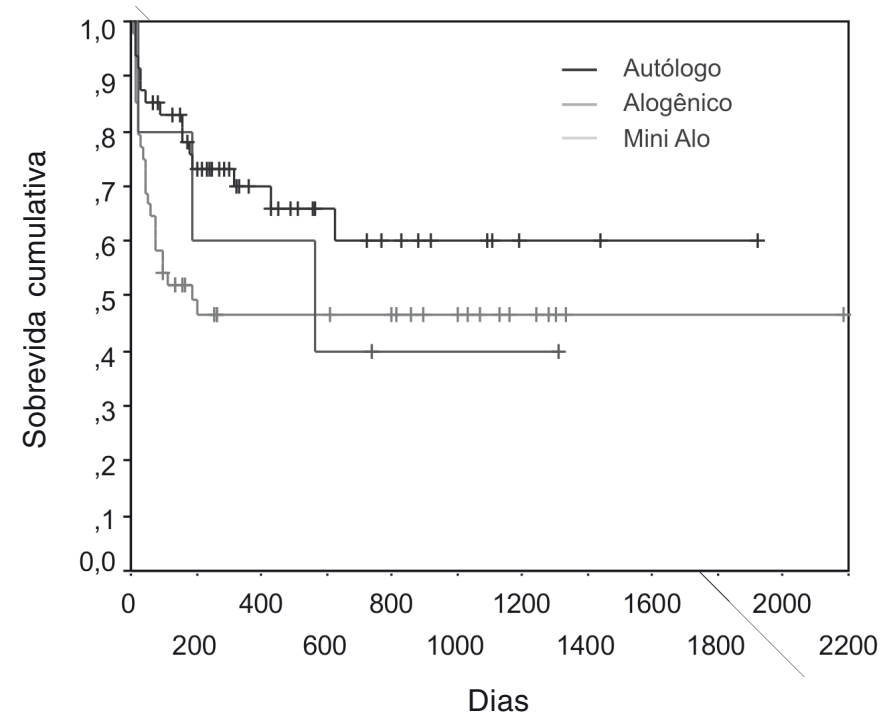

\section{DISCUSSÃO}

O TMO é um procedimento utilizado no tratamento de doenças oncológicas, hematológicas e imunológicas. No nordeste brasileiro, o câncer é a terceira causa de morte, perdendo em apenas $0,02 \%$ para as doenças infecciosas. Desta forma, a implantação de um centro de transplante de medula óssea se fazia imperioso para combater este importante problema de saúde pública. Apesar das grandes dimensões do estado da Bahia, existem poucos centros de referência para o tratamento de doenças onco-hematológicas fora da capital, o que acarreta inúmeras dificuldades para o diagnóstico e tratamento de tais patologias. O presente relato demonstra esta 
realidade, que faz com que os pacientes sejam encaminhados à unidade com longo tempo de diagnóstico, como é o caso da LMC e AAG ou já submetidos a vários esquemas prévios de quimioterapia, como no caso do MM e dos linfomas.

Apesar das dificuldades, os resultados observados em nossos pacientes foram semelhantes aos da literatura mundial.,15,16,17,18,19 Quando analisamos a SG nos 100 primeiros dias, em função do tipo de transplante, observamos que esta foi de $83 \%$ para TMO autólogo, $54 \%$ para TMO alogênico e $80 \%$ para os procedimentos não-mieloablativos. Quanto à SG em cinco anos de $52 \%$, esta também foi semelhante à de outros centros do Brasil. A mortalidade nos 100 primeiros dias após o transplante é usada para avaliar a toxicidade do procedimento, o que inclui a mortalidade relacionada à toxicidade do condicionamento como a doença veno-oclusiva hepática, as infecções, entre outras e, no caso dos TMO alogênicos, a DECH aguda. Esta taxa de mortalidade pode variar dependendo das condições do paciente, e do tipo de TMO, de menos de 5\% a mais de $40 \%$. Geralmente é maior no transplante alogênico do que no autólogo. ${ }^{1,16,20}$ Nesta nossa casuística, a mortalidade nos 100 primeiros dias foi de $31 \%$. Ao analisarmos a mortalidade, no TMO autólogo, esta foi de $17 \%$, no TMO alogênico foi de $46 \%$ e no mini-alo foi de $20 \%$. A nossa taxa de mortalidade, no caso do
TMO autólogo, encontra-se no limite superior quando comparado aos dados da literatura e isto se deve, provavelmente, à população de pacientes que nos é encaminhada com doença avançada e, na sua maioria, refratária. ${ }^{1,19,21}$

Quanto à causa de óbito, observamos que no TMO alogênico esta foi principalmente devido a DECH (38,2\%), o que vai de encontro aos dados da literatura mundial. Quando avaliamos o TMO autólogo, na nossa população as principais causas de óbito foram as infecciosas $(71,4 \%)$, diferentemente da literatura mundial, que aponta a recaída como causa principal. Esta divergência provavelmente se deve à combinação de fatores desde a situação clínica que estes pacientes apresentam quando nos são encaminhados, na sua maioria intensamente tratados previamente, aliada às condições sócio, cultural e econômica desfavoráveis da população, que prejudicam a aderência aos esquemas de profilaxias. ${ }^{1,22,23}$

\section{CONCLUSÃO}

Podemos concluir que o TMO na Bahia, apesar de todas as dificuldades impostas pela região, é factível e apresenta resultados satisfatórios que não divergem de outros grandes centros transplantadores do país.

\section{ABSTRACT}

Objective: This article presents the evolution of the first 100 transplanted patients in the Bone Marrow Transplantation Unit at Portuguese Hospital between February, 2000 and November, 2005. This unit is pioneer in the State of Bahia, Brazil, and one of the few transplant centers in the North and Northeast areas of the country. This is why this work is of major value. Methods: Forty-eight transplants were performed, being: myeloablative allogeneic, 5 non-myeloablative allogenic and 47 autologous. The mean age was 31 years, and most of them were male (59\%). Diagnoses were: chronic myeloid leukemia (20), aplastic anemia (11), acute myeloid leukemia (07), myelodysplastic syndrome (06), acute lymphoblastic leukemia (04), non-Hodgkin lymphoma (12), Hodgkin disease (13), multiple myeloma (21), and autoimmune disease (06). Results: The overall 5 years survival rate was 52\%, 60\% for the autologous BMT, 47\% for myeloablative allogeneic, and $40 \%$ for mini-allogeneic transplants. The mortality observed in the first 100 days was of $31 \%, 17 \%$ for autologous BMT, $46 \%$ for myeloablative allogeneic BMT, and 20\% for mini-allogeneic. Conclusion: Data shows that even with all the difficulty attributed to social, economic and cultural peculiarities of that region, BMT is a feasible procedure, and the obtained results were satisfactory and similar found in other transplantation centers in the country and all over the world.

Key words: Bone Marrow Transplantation, Immunology, Graft Rejection.

\section{REFERÊNCIAS}

1. Pasquini R. Transplante de medula óssea em 108 pacientes [tese]. Curitiba: Universidade Federal do Paraná; 1991.

2. Tabak DG. Transplante de medula óssea em leucemia mielóide aguda. Rev Bras Hematol Hemoter. 2000;22(1):55-62.

3. Maiolino A. O transplante de medula óssea no mieloma múltiplo. Rev Bras Hematol Hemoter. 2000;22(supl.esp):329-330.

4. Souza CA. Transplante de medula óssea em linfomas não-Hodgkin. Rev Bras Hematol Hemoter. 2000;22(supl.esp):333-334 .

5. Press OW. High dose chemotherapy with stem cell rescue for non-Hodgkin's lymphomas. Rev Bras Hematol Hemoter. 2000;22(supl.esp.):225-232.
6. Santini G, Congiu AM, Nati S et al. Autologous stem cell transplantation for agressive non-Hodgkin lymphomas. Rev Bras Hematol Hemot. 2002;24(2):85-90.

7. Voltarelli JC. Transplante de células tronco hematopoéticas para doenças auto imunes no Brasil. Rev Bras Hematol. Hemoter. 2002;24(1):9-14.

8. Marmont AM. Stem cell therapy for severe auto immune diseases. Rev Bras Hematol Hemoter. 2202;24(3):196-205.

9. Voltarelli JC. Hematopoietic stem cell transplantation for auto immune diseases in Brazil: current status and future prospectives. Rev Bras Hematol Hemoter. 2002; 24(3):206-211.

10. American Society for Blood and Marrow Transplantation. Conference synopsisHematopoietic stem cell therapy in autoimmune diseases, October 2001, Biology of blood and marrow transplantation. 2002;8:407-411. 
11. Carreras E, Saiz A, Marin Petal. CD 34+ selected autologous peripheral blood stem cell transplantation for multiple sclerosis: report of toxicity and treatment results at one year of follow up in 15 patients. Haematologica. 2003;88:306-314.

12. Gratwhol A, Baldomero, H, Horisberger B. Current trends in hematopoietic stem cell transplantation in Europe Blood. 2002;100(7):2374-2386.

13. Champlin RE. Non-myeloablative hematopoietic transplantation for treatment of malignant diseases. Current opinion in organ transplantation. 2002;7:275-278.

14. Burt RK, Deeg HJ, Lothian ST, Santos GW. On call in Bone Marrow Transplantation: RG Landes Company; 1996

15. Ministério da Saúde, Brasil, portaria 1217/GM de 13/10/1999. In Bouzas LF Transplante de medula óssea em pediatria e transplante de cordão umbilical. Medicina, Ribeirão Preto. 2000;33(3):241-263.

16. Ruiz MA, Zola PA, Homsi CM . Resultados da unidade de TMO/HB São José do Rio Preto, São Paulo-Brasil. Rev Bras Hematol Hemoter. 2000;22(supl):29, abstract 63.

17. Urbano-Ispizua A. Acreditacíon de centros de TPH. In: Carreras E, Brunet S, Ortega JJ, Rovira M, Sierra J, Urbano-Ispizua A. Manual de Transplante Hempoyético. $2^{\mathrm{a}}$ ed., Espanha, Editorial Antares, 2002. p.21-28.
18. Federl S, Talpaz M, Estrov Z, Kantarjian HM. Chronic myelogenous leukemia: biology and therapy. Annals of Internal Medicine. 1999;131(3):207-219.

19. Ruiz MA, Piron-Ruiz L, Zola PA, Faria CMM, Melo E, Junior ASS et al. Transplante de medula óssea: A evolução e os resultados do Hospital de Base de São José do Rio Preto-São Paulo-Brazil. J. Bras. de Transp. 2004;7(1):34-39.

20. Dulley, F.L; Kanfer, EJ; Appelbaum, F.R; Amos, D; Hill, R.S; Buckner, C.D et al. Venocclusive disease of liver after chemotherapy and autologous bone marrow transplantation. Transpl. 1987;43(6):870-3

21. The International Bone Marrow Transplant Registry/ Autologous Bone Marrow Transplant Registry. Report on state of the art blood and marrow transplantation (summary slides with guide). Newsletter special millennium edition. 2007;7(1):3-10.

22. Vogelsang, G.V. Acute graft versus host disease following marrow transplantation. Marrow Transplant. Rev. 1993;2(4):49-53.

23. Saboya, R. Infecções bacterianas e fúngicas no transplante de medula óssea - análise de 186 casos [tese]. São Paulo: Universidade de São Paulo; 1998 